\title{
Secondary bilateral synchrony in unilateral pial angiomatosis: successful surgical treatment
}

\author{
JEAN-JACQUES CHEVRIE, * NORMA SPECOLA, JEAN AICARDI* \\ From the Institut National de la Santé et de la Recherche Médicale, ${ }^{*}$ and Département de Pédiatrie, Hôpital des \\ Enfants Malades, Paris, France
}

SUMMARY Three children with circumscribed unilateral pial angiomatosis had both generalised and partial seizures associated with bilateral synchronous spike-wave complexes. Dramatic control of the seizures was obtained by surgical removal restricted to the angiomas and underlying cortex. There was recurrence of seizures in one patient from whom only one of two angiomatous areas was removed but not in the two patients whose excision was total. These cases indicate that secondary bilateral synchrony can occur with lesions of the posterior and external parts of one hemisphere. Surgical removal of a definable lesion, without intracranial recording, can help patients with intractable epilepsy due to unilateral pial angiomatosis, even in the presence of wide diffusion of clinical and electroencephalographic abnormalities.

The occurrence of generalised seizures associated with bilateral synchronous spike-wave or polyspike-wave complexes in patients with localised brain lesions is usually regarded as a contra-indication to their surgical removal, at least for the treatment of the epilepsy. With such findings it is difficult to ensure that the epileptogenic area is localised, single and stable, which is the generally accepted requirement for considering its surgical removal. ${ }^{1-5}$

Invasive investigations using intracranial electrodes could help solve this problem, but their complexity and cost restrict their use to a few selected patients.

We report the case of three patients with unilateral, localised pial angiomatosis confirmed at surgery, who had generalised seizures and bilateral synchronous EEG paroxysms without any localising feature, for whom surgical removal of the lesion and underlying cortex was followed by disappearance of the seizures and of the EEG paroxysms. One of these patients had classical Sturge-Weber disease with facial angiomatosis (case 3). The two other children had isolated unilateral pial angiomas and cortical calcification without facial involvement. None had any familial history of epilepsy.

\footnotetext{
Address for reprint requests: J J Chevrie, MD, Unité de Neurologie, Département de Pédiatrie, Hôpital des Enfants Malades, 75743 Paris Cedex 15, France.
}

Received 28 August 1987 and in revised form 1 December 1987. Accepted 24 December 1987

\section{Case reports}

Case 1

This 15 year old normally developed boy first had a brief right-sided partial motor seizure at age 7 years. At 9 years of age, he had a further motor seizure with onset in the right upper limb with secondary generalisation. Neurological examination was normal. No facial angioma was present but skull radiographs showed "tram track" left-sided parietal calcification. Left carotid angiography was normal. The EEG revealed left posterior slow waves and bilateral spikes predominantly over the left hemisphere. He was given phenobarbitone. Seizures recurred 1 year later at 10.5 years of age and persisted over the following years despite multiple anticonvulsant drug regimens (phenobarbitone, carbamazepine, sodium valproate, ethosuximide). The seizures were of several types: partial motor seizures with or without impairment of consciousness, at times followed by automatisms; tonic-clonic seizures with fall; masticatory seizures; fragmentary myoclonus. The seizures often occurred in clusters. In the period preceding surgery, there were 10-15 seizures a day. At age 15 years 9 months neurological and ophthalmological examination was normal as was mental development. A computed tomography (CT) scan showed left posterior parietal calcification. Digitalised angiography was normal. EEGs showed long runs of irregular bilateral synchronous spike-wave complexes that occurred spontaneously and during hyperventilation without focal abnormalities (fig 1). Because of the frequent, intractable seizures, the patient was operated on at age 16 years. The pial angioma located over the posterior part of the left parietal lobe was totally removed together with the underlying calcified cortex. Pathological examination confirmed the existence of a leptomeningeal angioma overlaid by a fibro-adipous cush- 


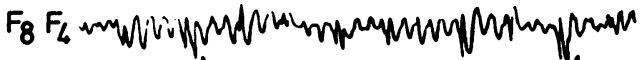

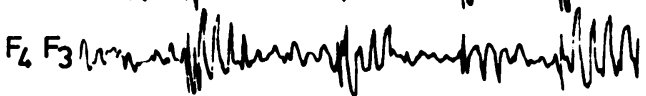

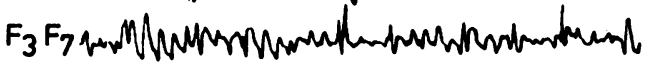

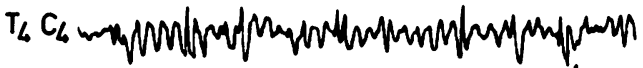

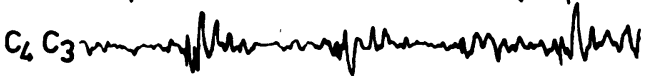

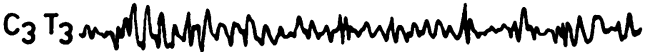

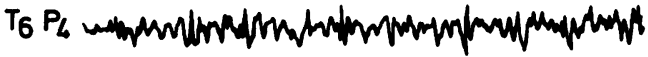

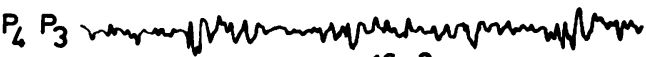

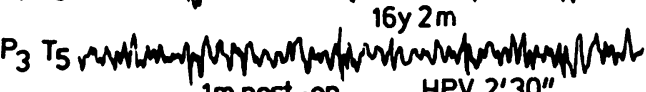

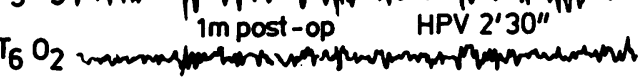
27.07.84

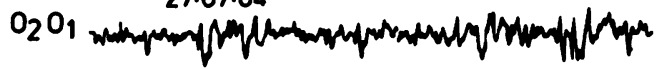

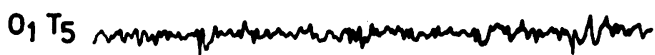

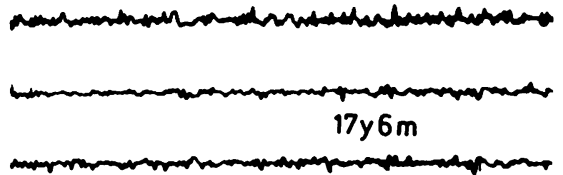

$18 \mathrm{~m}$ post-op

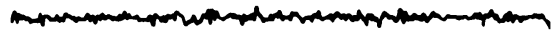

18.12.85

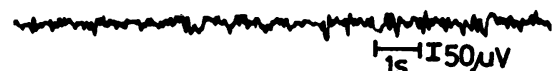

is II50 uV

Fig 2 Case 1. Left: One month post-operatively. Persistence of short bursts of bilateral polyspike-wave complexes during hyperventilation (HPV). Right: 18 months post-operatively. No paroxysms are visible. 


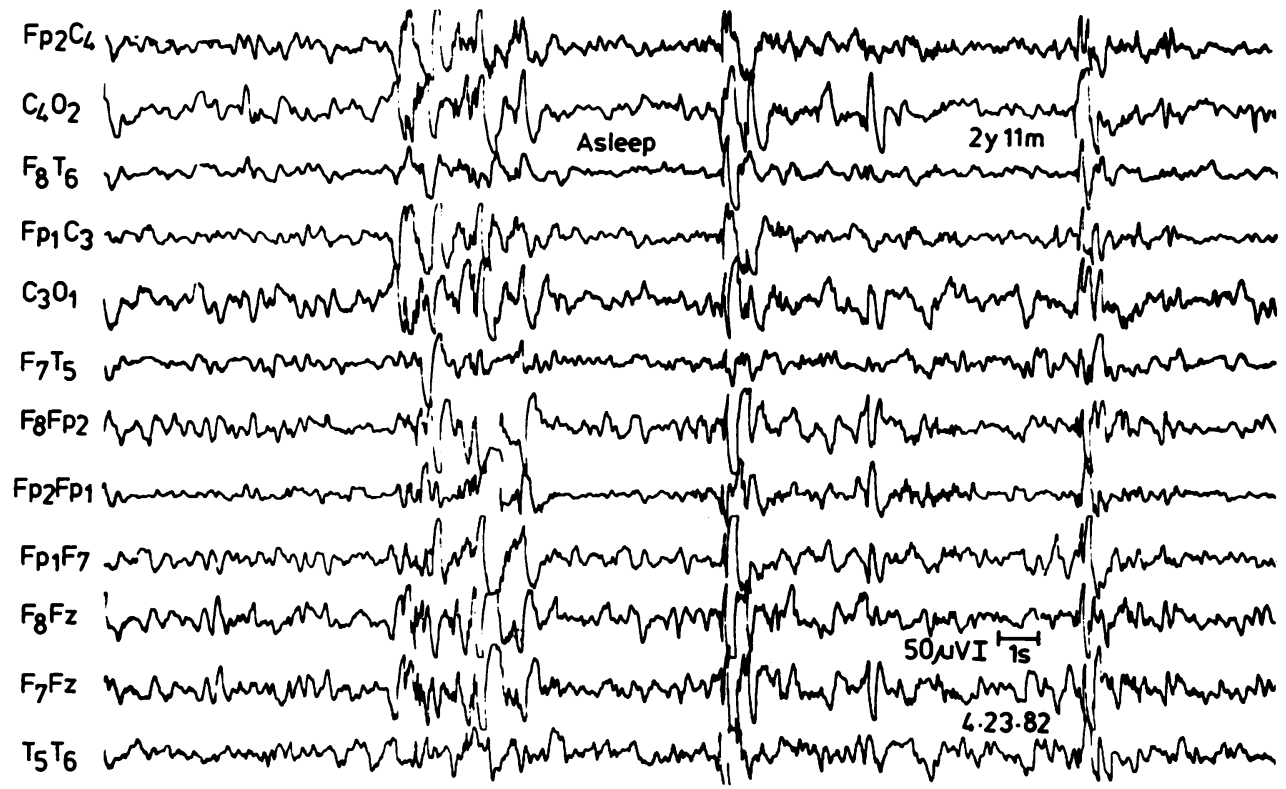

Fig 3 Case 2. Pre-operative record. Bursts of high voltage spike-wave complexes during slow sleep. Each burst was accompanied by jerks of all four limbs.

ion, and extensive deep cortical calcification. The seizures have not recurred since surgery. One month after operation the EEG still showed a few bursts of bilateral spike-waves during hyperventilation (fig 2). Thirty months later, neurological examination remained normal, as was the EEG (fig 2). Anticonvulsant drugs had been discontinued and the patient's scholastic performance was superior.

Case 2

This 2 year 8 month old girl without a history of neurological disorders had a first epileptic attack at age 16 months. The seizure involved the left half of the face. It lasted for 1 hour, was accompanied by loss of consciousness, and followed by transient left facial palsy. The EEG revealed right occipital delta waves that had disappeared 1 week later. Plain skull radiographs were normal. Following a seizurefree period of 13 months without drug treatment, the seizures recurred at age 29 months. They occurred several times a day and were never controlled by antiepileptic drugs (carbamazepine, sodium valproate, phenobarbitone, clobazam, ethosuximide, clonazepam). The seizures were of several types: left-sided facial clonic seizures; clonic seizures involving the left arm and leg; falls of the head associated with tonic contractions of the left lower limb with fall; atonic seizures; clusters of flexion of the head and limbs resembling infantile spasms. An EEG at 35 months of age showed diffuse slow waves while awake and bilateral bursts of polyspikes and slow waves without focal features, some of them associated with clonic jerks of all four limbs during sleep (fig 3). Neurological examination was unremarkable except for left-sided homonymous hemianopia. Mental development that had been normal up to the age of 29 months now had slowed down. At age 3 years 10 months the developmental quotient was 65. CT showed right occipital calcification. Right carotid angiography was normal. While the child was having a series of infantile spasms, interictal records revealed long runs of irregular, bilateral synchronous spikewave complexes, polyspike-wave complexes and slow spikewaves during wakefulness (fig 4). During sleep numerous bursts of bilateral polyspikes and polyspike-wave complexes were observed (fig 4). The child was operated on at 4 years 1 month of age. The right occipital lobe was resected "en bloc". Pathological examination confirmed the presence of leptomeningeal angiomatosis with neuronal loss, gliosis and calcification in the underlying cortex. Forty-five months after operation, the child remains seizure-free, and, except for some spikes recorded during sleep for the first 3 months, no paroxysm has been seen on the postoperative EEG records (fig 5). Except for homonymous hemianopia, neurological examination has remained normal. The IQ at 6 years 10 months was 85 .

\section{Case 3}

This 8 year 11 month old girl was free of neurological abnormality until the age of 7 years. She then started having seizures. The first three attacks consisted of a brief fall accompanied by pain in the left lower limb and followed by headache. On the same day she had another seizure that started with headache and pain in the left limbs, followed by head turning towards the left, loss of consciousness and clonic jerks of both upper limbs. Several seizures with paroxysmal pain in the left limbs with or without headache 


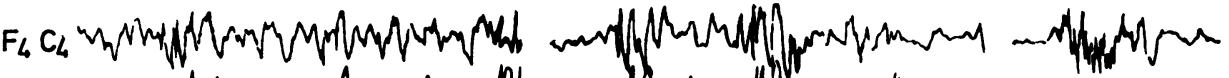

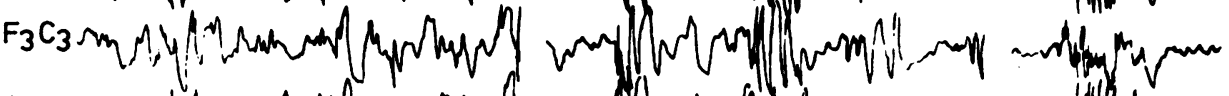

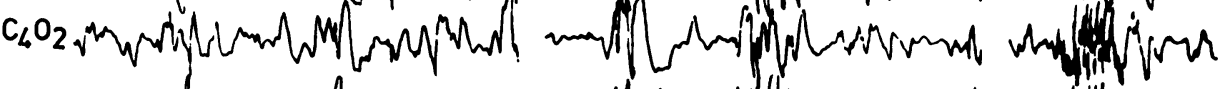

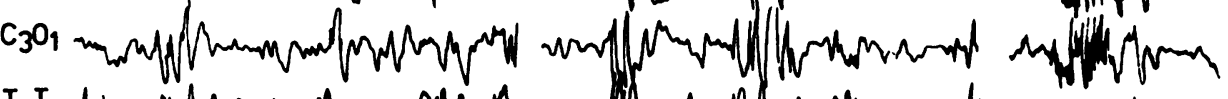
$T_{6} T_{6}$ 4.

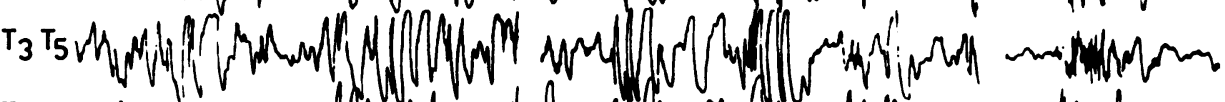

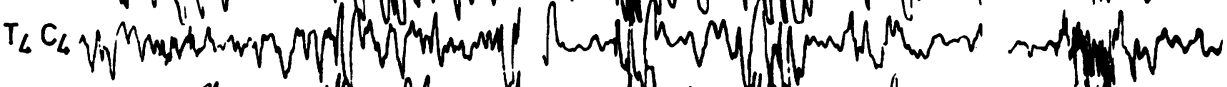

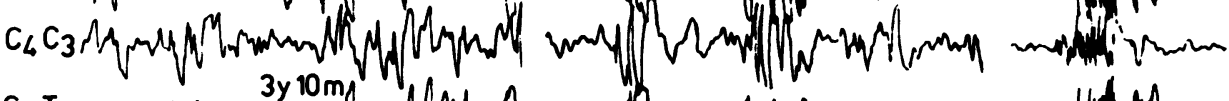

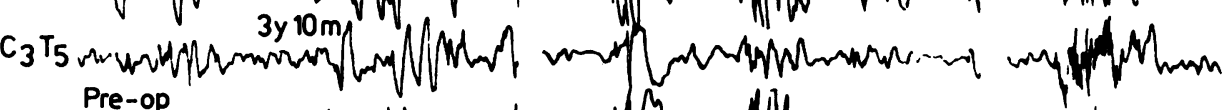

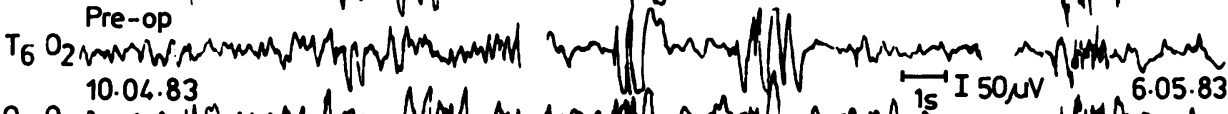

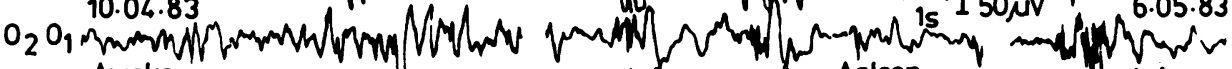

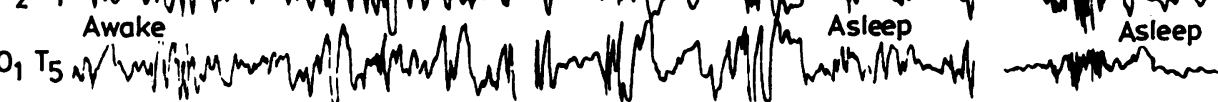

Fig 4 Case 2. Pre-operative records. Left: Bilateral synchronous spike-wave complexes while awake. Middle: same age. Polyspike-wave complexes during slow sleep. Right: One month later, runs of polyspikes during slow sleep.
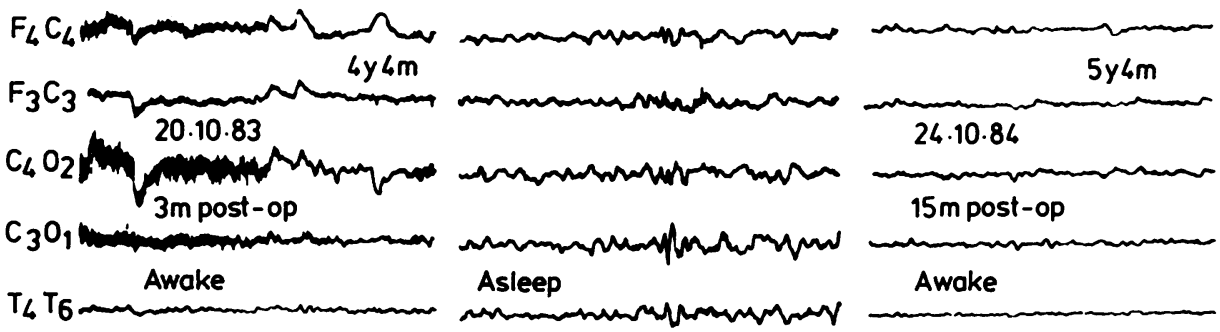

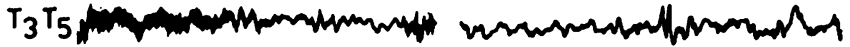

$\mathrm{T}_{4} \mathrm{C}_{4}$

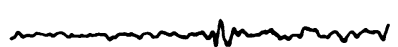

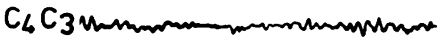

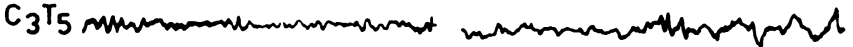
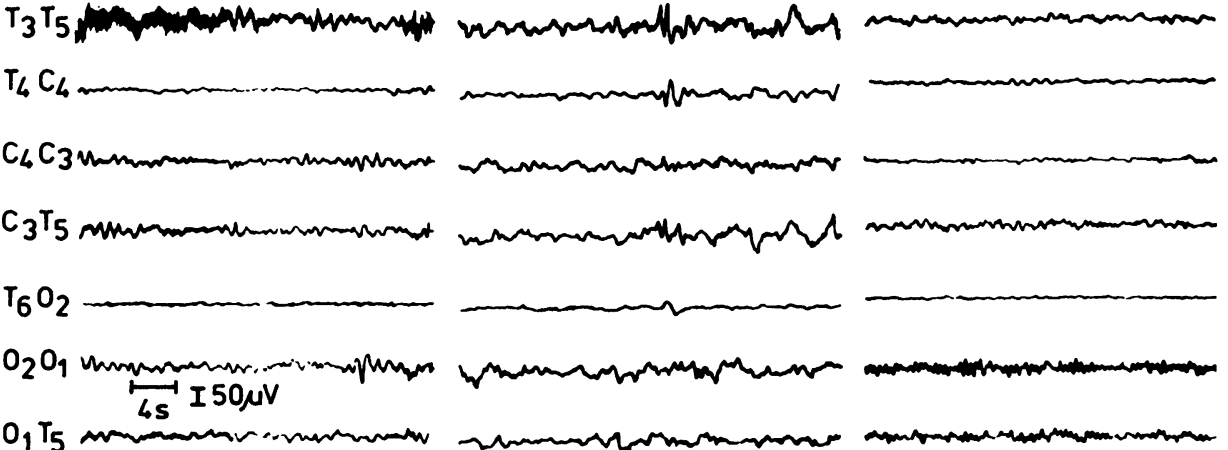

Fig 5 Case 2. Left and middle: records taken 3 months post-operatively. A few spikes persist during slow sleep. Right: 15 months post-operatively. Disappearance of paroxysmal abnormalities. 


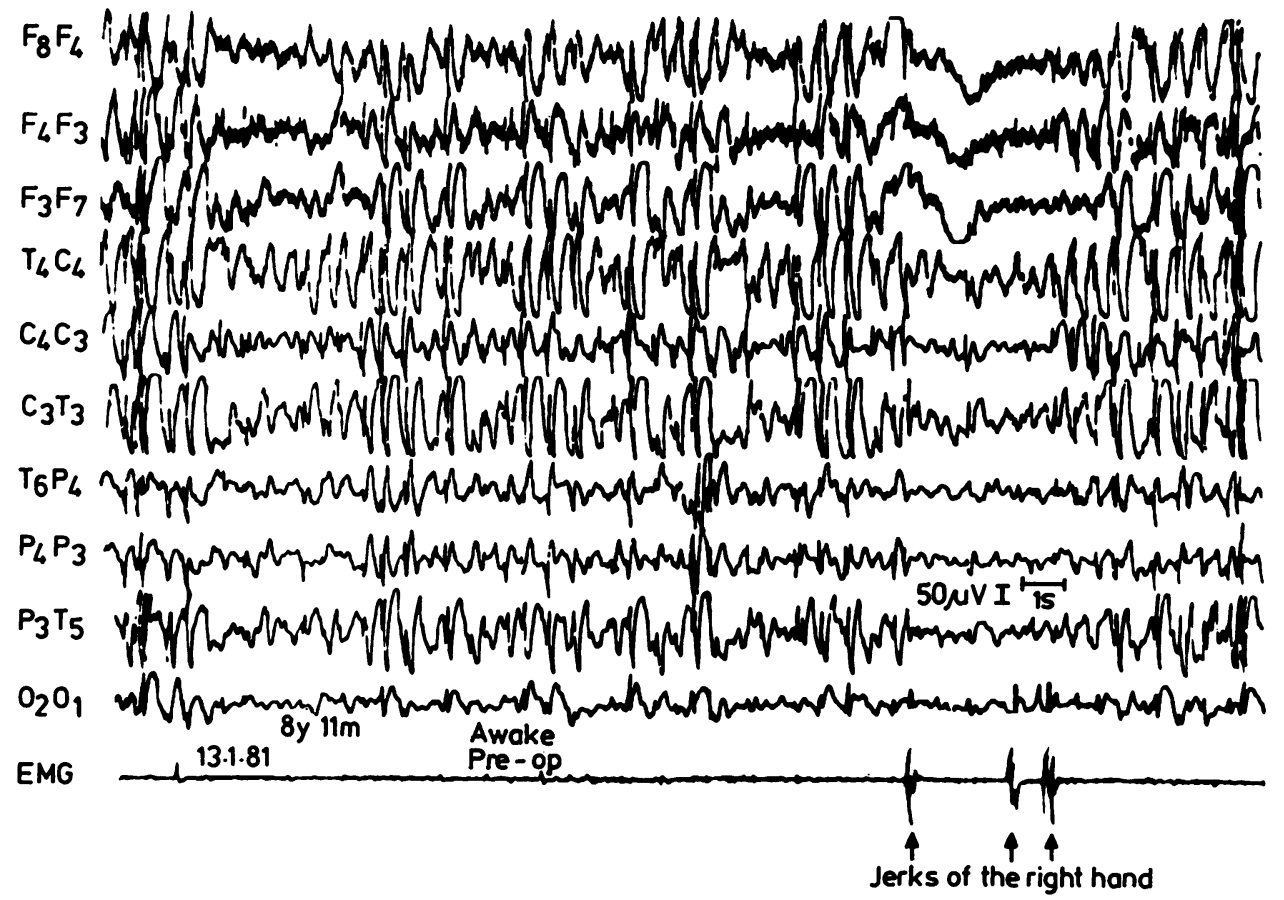

Fig 6 Case 3. Pre-operative record. Almost continuous bilateral synchronous slow spike-wave complexes. No focal paroxysms are associated with the jerks of the right hand (EMG).

occurred over the next few days. Neurological examination was normal. The patient was given phenobarbitone and phenytoin, and was seizure-free for 7 months. Seizures then recurred and became very frequent, up to several dozen daily. They consisted of a sudden fall forward without obvious impairment of consciousness or of localised paraesthesiae or pain involving the left upper limb. The EEG record showed a depressed background activity over the right hemisphere and spikes or bilateral synchronous irregular spike-wave complexes, of higher amplitude over the posterior half of the right hemisphere but without clear focal features. Right carotid angiography was unremarkable. The IQ was 89. Seizures persisted with the same frequency despite trials of many antiepileptic drugs (phenobarbitone, phenytoin, carbamazepine, sodium valproate, clonazepam) and corticosteroids. They were of many different types: falls, head myoclonias, erratic myoclonus of the fingers, axial tonic seizures, left partial sensory seizures, episodes of nonconvulsive status epilepticus. A CT scan at age 8 years 11 months showed right temporo-occipital calcification and, after contrast infusion, cortical enhancement over the right parieto-temporal region suggestive of a pial angioma. The interictal EEG showed almost continuous discharges of bilateral synchronous slow spike-wave complexes without focal abnormalities even during clonic jerks of the right hand (fig 6). Clinical examination was normal. The patient was referred to a specialised centre for stereotaxic EEG exploration. In view of the EEG and clinical picture that was considered indicative of bilateral disease, this investigation was refused. The child's status remained unchanged until age 10 years when she was finally operated on elsewhere without further exploration. Operation disclosed the presence of two pial angiomas over the right hemisphere: one involved the internal and external aspects of the parietal lobe, the other covered the lower part of the right temporal lobe and extended posteriorly to the external aspect of the occipital lobe. Only the parietal lesion was removed. Postoperatively there was a permanent left hemiparesis but both the seizures and the EEG abnormalities totally disappeared (fig 7). The patient resumed attendance at school which had been interrupted because of the frequent seizures. The remission lasted for 21 months during which she continued to receive anticonvulsant therapy. At age 11 years 11 months, the seizures recurred with increasing frequency despite antiepileptic agents (phenobarbitone, clonazepam, primidone, progabide, carbamazepine, stiripentol). The seizures included atypical absences; left partial motor seizures with or without sensory manifestations; attacks of fear with head turning to the left, extension of the limbs, loss of consciousness and fall; perception of coloured lights. The EEG again demonstrated numerous bursts of bilateral, synchronous spike-wave and slow polyspike-wave complexes. On CT, the temporo-occipital calcification was more visible. At age 13 years 10 months, the patient had up to 30 or $\mathbf{4 0}$ seizures daily and school attendance was again impossible. $\mathrm{Re}$-operation was refused by the neurosurgeons. 

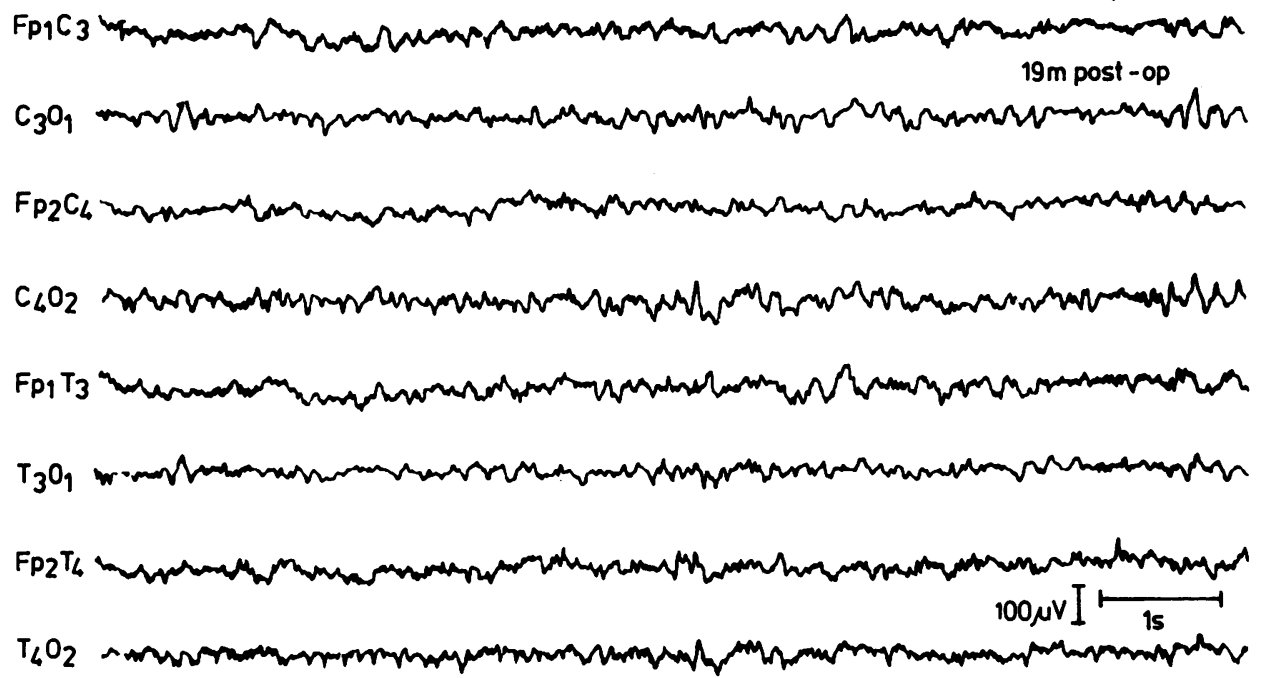

Fig 7 Case 3. Nineteen months post-operatively, no paroxysm recorded.

\section{Discussion}

Bilateral synchronous spike-waves or polyspikewaves on EEG recordings (bilateral synchrony) belong to two main categories. ${ }^{67}$ Primary bilateral synchrony is unassociated with detectable brain lesions and is usually observed in epilepsy with a strong genetic component, the so-called "centrencephalic, ${ }^{7}$ or "cortico-reticular"8 epilepsies. Secondary bilateral synchrony ${ }^{79}$ is thought to originate from a limited area of abnormal cortex in one hemisphere and to spread rapidly to both sides.

Some authors have used corticography and electrical stimulation to demonstrate the localised origin of the discharges from parasagittal foci. ${ }^{79}$ Others have required the presence on the scalp EEG of a sequence of focal spikes or sharp waves lasting at least 2 seconds, immediately preceding the bursts of bilateral synchronous spike-wave complexes. ${ }^{10}$ Still others accept the diagnosis of secondary bilateral synchrony when a paroxysmal EEG focus and bursts of synchronous spike-waves coexist, even though there is no strict temporal relationship between the focal and the bilateral paroxysmal activity. ${ }^{11-13}$

The differentiation between primary and secondary bilateral synchrony is difficult because patients with localised cortical foci can have predominantly generalised seizures. ${ }^{14-23}$

The following arguments can help separate secondary from primary bilateral synchrony. (1) The appearance of the spike-wave complexes may be slower and less regular in secondary than in primary bilaterat synchrony. ${ }^{9}$ However, localised frontal stimulation in 3 epileptic patients can induce classical $3 \mathrm{~Hz}$ regulag discharges. $^{1415}$ (2) Intracarotid injection of ambs. $\overrightarrow{0}$ lobarbitone and pentilenetetrazol ${ }^{24-26}$ or the endese venous injection of thiopental ${ }^{20}$ have not gained wide acceptance. (3) A major argument is the presence of a radiologically demonstrable localised brain lesion. (4) Recording with intracranial electrodes of spontaneous or provoked seizures can detect focal ictal discharges that may trigger secondary generalisation. ${ }^{11415}$ Such methods explore only part of the $\overrightarrow{\overrightarrow{0}}$ brain. Thus a focal discharge preceding a bilateral $\exists$ spike-wave can be missed. Finding a focal discharge does not exclude the possibility of multiple or diffuse epileptogenic areas. Moreover the safety of inserting depth electrodes into or around a pial angioma remains in doubt. (5) Disappearance of generalised $:$ seizures and paroxysmal EEG activity after removal 3 . of a localised cortical lesion is a convincing demon- $\delta$ stration of the secondary nature of bisynchronous paroxysmal activity, ${ }^{1791012-1417232728}$ even for 을 cases in which no EEG focus was present. ${ }^{17232728}$

Our three patients had circumscribed lesions whose removal was followed by disappearance of the seizures and of the bilateral EEG paroxysms. All of $\sigma$ them had both partial and generalised seizures: simple $N$ or complex partial seizures, purely motor in type in $\mathbb{N}^{-}$ cases 1 and 2, and mixed sensory and motor in case 3 ; 0 generalised motor seizures with or without focal onset (cases 1, 2, 3), including infantile spasms (case 3). In 
all the patients, the interictal paroxysmal EEG discharges were exclusively bilateral and synchronous, reinforced by hyperventilation in case 1 and by sleep in case 2 . No focal discharge was ever observed on any interictal record. Ictal records in cases 2 and 3 did not allow determination of the origin of the seizures. No pharmacological test was performed. Removal of the angioma was followed by dramatic disappearance of the seizures and, with a slight delay in patients 1 and 2 , by that of the EEG discharges. This result excludes multiple or diffuse brain damage as the cause of seizures and EEG paroxysms, and is strong evidence for secondary bilateral synchrony. Incidentally it shows that the origin of secondary bilateral synchrony is not restricted to the mesial aspect of the frontal or temporal lobe, ${ }^{179-111415172728}$ but can occur with lesions in the posterior and external parts of the brain. ${ }^{11131623}$

Patients 1 and 2, for whom total removal of the lesion was performed, remain seizure-free 30 and 45 months respectively after operation. Recurrence of seizures in patient 3 following a 21 -month seizure-free period suggests that the temporo-occipital angioma left in place is responsible for the reappearance of attacks, and that further operation should be considered.

Surgical treatment for unilateral pial angiomatosis remains controversial..$^{29-33}$ Early operation has been advocated because the neurological manifestations of Sturge-Weber disease seem to be progressive in many cases. ${ }^{293133}$ However, late operation in our patients (respectively 9 years, 33 months, and 3 years after their first epileptic seizure) still gave favourable results.

It is our contention that surgical treatment of unilateral pial angiomatosis is indicated when the associated epilepsy is not controlled by anticonvulsant drugs, regardless of seizure types and location of EEG abnormalities, even when invasive diagnostic techniques are not available.

We thank Drs Misès and Salefranque (EEG Department) for the EEG records; Drs Hirsch, Renier, Pierre-Kahn, and Sainte-Rose who operated on patients 1 and 2. Dr Herranz (Santander, Spain) kindly referred patient 3 and provided clinical information on her follow-up.

\section{References}

1 Munari C, Bancaud J. The role of stereo-electroencephalography (SEEG) in the evaluation of partial epileptic seizures. In: Porter RJ, Morselli PL, eds. The Epilepsies. London: Butterworths, 1985:267-306.

2 Walker AE. Surgery for epilepsy. In: Vinken PS, Bruyn GW, eds. Handbook of Clinical Neurology, Vol 15. Amsterdam: North Holland Publishing Company, 1974:739-57.
3 Ward AA Jr. Theoretical basis for surgical therapy of epilepsy. In: Purpura DP, Penry JK, Walter RD, eds. Neurosurgical Management of the Epilepsies. New York: Raven Press, 1975;23-5.

4 Ward AA Jr. Surgical management of epilepsy. In: Browne TR, Feldman RG, eds. Epilepsy. Diagnosis and Management. Boston: Little Brown and Company, 1983:281-96.

5 Ward AA Jr. Perspectives for surgical therapy of epilepsy. In: Ward AA Jr, Penry JK, Purpura DP, eds. Epilepsy. New York: Raven Press, 1983:371-90.

6 Gloor P. Neurophysiological basis of generalized seizures termed centrencephalic. In: Gastaut H, Jasper H, Bancaud J, Waltregny A, eds. The Physiopathogenesis of the Epilepsies. Springfield: Charles C Thomas, 1969:209-36.

7 Penfield W, Jasper H. Epilepsy and the Functional Anatomy of the Human Brain. Boston: Little Brown and Company, 1954:605-15.

8 Gloor P. Generalized cortico-reticular epilepsies. Some considerations on the pathophysiology and generalized bilaterally synchronous spike and wave discharge. Epilepsia 1968;9:249-63.

9 Tückel K, Jasper $H$. The electroencephalogram in parasagittal lesions. Electroencephalogr Clin Neurophysiol 1952;4:481-94.

10 Blume WT, Pillay N. Electrographic and clinical correlates of secondary bilateral synchrony. Epilepsia 1985;26:636-41.

11 Gabor AJ, Ajmone Marsan C. Co-existence of focal and bilateral diffuse paroxysmal discharges in epileptics. Epilepsia 1969;10:453-72.

12 Niedermeyer E. The occurrence of generalized (centrencephalic) and focal seizure patterns in the same patient. Bull Johns Hopkins Hosp 1968;122:11-25.

13 Niedermeyer E. The Generalized Epilepsies, a Clinical Electroencephalographic Study. Springfield: Charles C Thomas, 1972:37-44.

14 Bancaud J. Physiopathogenesis of generalized epilepsies of organic nature (stereo-electroencephalographic study). In: Gastaut H, Jasper H, Bancaud J, Waltregny A, eds. The Physiopathogenesis of the Epilepsies. Springfield: Charles C Thomas 1969:158-85.

15 Bancaud J, Talairach J, Morel P, et al. "Generalized" epileptic seizures elicited by electrical stimulation of the frontal lobe in man. Electroencephalogr Clin Neurophysiol 1974;37:275-82.

16 Blom S, Von Essen C, Silfvenius H, Zetterlund B. Epilepsy surgery in 18 children: early results. Acta Paediatr Scand 1985; Suppl 322:2.

17 Farwell JR, Stuntz JT. Frontoparietal astrocytoma causing absence seizures and bilaterally synchronous epileptiform discharges. Epilepsia 1984;25:695-8.

18 Fukuyama Y, Tsuchiya S. A study on Sturge-Weber syndrome. Report of a case associated with infantile spasms and electroencephalographic evolution in five cases. Europ Neurol 1979;18:194-204.

19 Geier S, Bancaud J, Talairach J, et al. The seizures of frontal lobe epilepsy. A study of clinical manifestations. Neurology 1977;27:951-8.

20 Lombroso CT, Erba C. Primary and bilateral synchrony in epilepsy: a clinical and electroencephalographic study. Arch Neurol 1970;22:321-34.

21 Millichap JG, Bickford RG, Klass DW, Backus RE. Infantile spasms, hypsarrhythmia and mental retardation. A study of etiological factors in 61 patients. Epilepsia 1962;3:188-97.

22 Pazzaglia A, D'Allessandro R, Ambrosetto G, Lugaresi E. Drop attacks: an ominous change in the evolution of partial epilepsy. Neurology 1985;35:1725-30.

23 Rosen I, Salford L, Starck L. Sturge-Weber disease. Neurophysiological evaluation of a case with secondary epileptogenesis, successfully treated with lobe-ectomy. Neuropediatrics 1984;15:95-8.

24 Gloor P. Contributions of electroencephalography and electrocoticography to the neurosurgical treatment of epilepsies. In: 
Purpura DP, Penry JK, Walter AD, eds. Neurosurgical Management of the Epilepsies. New York: Raven Press, 1975:59-105.

25 Gloor P, Rasmussen T, Altuzarra A, Garreston H. Role of the intracarotid amobarbital-pentylenetetrazol EEG test in the diagnosis and surgical treatment of patients with complex seizure problems. Epilepsia 1976;17:15-31.

26 Rovit RL, Gloor P, Rasmussen T. Intracarotid amobarbital in epileptic patients. Arch Neurol 1961;5:606-26.

27 Gastaut H, Mouren P, Paillas JE. A propos de la "bisynchronie secondaire" en électroencéphalographie: paroxysmes bilatéraux, synchrones et symétriques révélateurs d'un abcès temporal. Rev Neurol (Paris) 1968;119:295-8.

28 Honda K, Shinomiya N, Nomura Y, et al. Effects of neurosurgical treatment on diffuse slow spike and wave complex: a case of left frontal mass lesion with diffuse slow spike and wave complex (DSSW). Brain Dev 1985;7:496-9.

29 Alexander GL. Sturge-Weber syndrome. In: Vinken PJ, Bruyn GW, eds. Handbook of Clinical Neurology, Vol 14. Amsterdam: North Holland Publishing Company, 1972:223-40.

30 Buttler G, Schulte FJ. Zur operativen Behandlung des SturgeWeber Syndroms. Neuropädiatrie 1975;6:135-41.

31 Hoffman AJ, Hendrick EB, Dennis M, Armstrong D. Hemispherectomy for Sturge-Weber syndrome. Child's Brain 1979, 5:233-48.

32 Rasmussen T, Mathieson G, Le Blanc F. Surgical therapy of typical and a forme fruste variety of the Sturge-Weber syndrome. Arch Suisses Neurol Neurochir Psychiatrie 1972;111:393-409.

33 Revol M, Gilly R, Challamel MJ, et al. Epilepsie et maladie de Sturge-Weber. Boll Lega Ital Epilepsia 1984;45/46:51-8. 